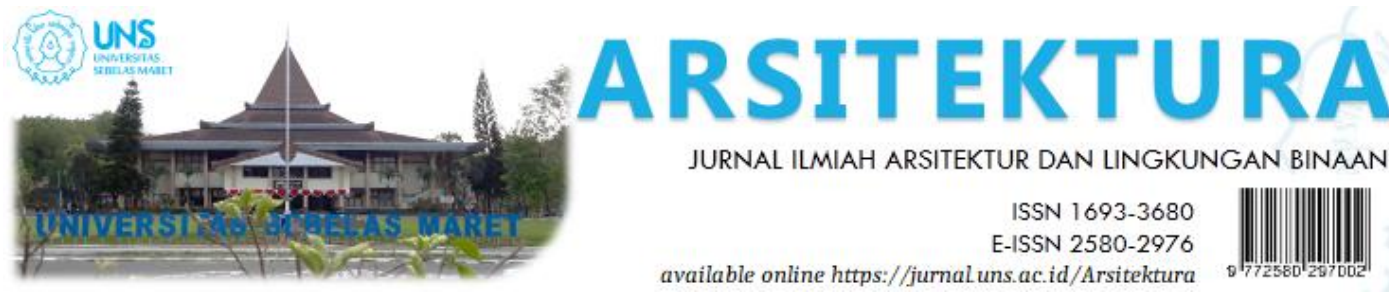

Volume 19 Issue 2 October 2021, pages:231-238

\title{
Konstruksi Atap Rumah yang Tanggap Terhadap Pasir Vulkanik pada Kawasan Wisata Gunung Agung di Bali
}

\section{The construction of vulcanic sand resistant house roof in the tourism area of Mount Agung, Bali}

\author{
Dinar Sukma Pramesti ${ }^{1 *}$, A.A. Ketut Sri Candrawati ${ }^{2}$ \\ Politeknik Internasional Bali ${ }^{*}$ \\ dinar.pramesti@pib.ac.id \\ Politeknik Internasional Bali
}

DOI: https://doi.org/10.20961/arst.v19i2.49888

Received: March 29,2021 Revised: October 12,2021 Accepted: October 12,2021 Available online: October 30,2021

\begin{abstract}
The area around Mount Agung needs a roof design that can give extra protection for the residents. The volcanic sand may cause serious danger and damage to the residents' houses since it brings a heavy load to the roof. It causes roof collapses and it dangers the residents' safety. This study was a Research and Development Research and Development by Borg and Gall with a mixed method. Roof testing was done by carrying out an FGD by inviting one expert to provide input on the quality of the product, for revising and reporting the results according to the improvements. Based on the study, it was found (1) the needs of the residents due to the roof design, (2) the suitable type of roof that is resistant to the volcanic sand, and (3) the suitable roof construction for the residents around Mount Agung. The results of the study are expected to contribute to the construction design of residents' houses around Mount Agung that can protect them from the volcanic sand.
\end{abstract}

Keywords: roof construction; volcanic sand; Mount Agung

\section{PENDAHULUAN}

Gunung Agung merupakan salah satu destinasi wisata di Bali yang mulai kurang diminati oleh wisatawan untuk berkunjung dikarenakan erupsi Gunung Agung yang terjadi pada tanggal 21 november 2017. Erupsi tersebut memberikan banyak pelajaran bagi warga masyarakat di sekitar untuk lebih waspada dan melakukan antisipasi apabila suatu ketika Gunung Agung akan erupsi kembali.

Salah satu dampak erupsi Gunung Agung terhadap bangunan adalah pada bagian atap bangunan. Atap bangunan tertimbun pasir vulkanik hingga menyebabkan bangunan menjadi ambruk. Selain itu, pasir vulkanik yang berada di atas atap menyulitkan pemilik rumah dalam membersihkannya karena harus ke atas atap. Kegiatan tersebut berbahaya dilakukan. Besar kemungkinan akan terjatuh dari atas atap.

Dalam rangka menciptakan keamanan dan kenyamanan bagi wisatawan maupun masyarakat di sekitar daerah Gunung Agung diperlukan suatu desain atap rumah yang tahan terhadap bahaya pasir vulkanik.

Konstruksi atap pada bangunan merupakan komponen bangunan yang sangat penting. Atap pada bangunan yang berada pada posisi 
paling atas bangunan, berfungsi sebagai penutup seluruh ruangan yang ada di bawahnya terhadap pengaruh panas, debu, hujan, angin atau untuk keperluan perlindungan. Oleh karenanya, atap sebaiknya didesain dengan konstruksi ringan, sehingga apabila ada dampak yang memberikan pengaruh dari luar terhadap konstruksi dan penutupnya baik terhadap suhu (sinar matahari), cuaca (air hujan dan kelembaban udara), serta keamanan terhahap gaya horizontal (angin dan gempa), pasir vulkanik dan kebakaran, bangunan harus tetap kokoh dan dijamin aman.

Perkembangan bidang konstruksi atap sebenarnya sudah lama dilakukan oleh para ahli konstruksi, tetapi pada waktu sebelumnya masyarakat belum mengenal atau belum memperdalam pengetahuan akan konstruksi baja ringan yang ternyata mempunyai sifat lebih efisien sehingga biaya perawatan lebih murah, serta memiliki keunggulan lain. Pada saat ini, konstruksi baja telah diuji dan mempunyai keunggulan yaitu lebih tahan lama jika digunakan rangka atap dengan bahan baja ringan tersebut daripada menggunakan bahan dasar rangka kayu sebagai penopang konstruksi atap rumah mereka. Namun demikian konstruksi atap kayu masih banyak digunakan, karena kemudahan untuk mendapatkan bahan. Kontsruksi atap dengan bahan kayu maupun baja ringan memiliki kekurangan dan kelebihannya sendiri-sendiri.

Adapun tujuan khusus dalam penelitian ini adalah untuk; (1) menganalisis kebutuhan warga terhadap atap rumah yang sesuai diguanakan untuk daerah di sekitar gunung agung, (2) mengidentifikasi jenis atap rumah yang tahan terhadap bahaya pasir vulkanik, dan (3) mendesain konstruksi atap rumah bagi warga di sekitar gunung agung agar tahan terhadap pasir vulkanik. Sementara, urgensi dari penelitian ini adalah (1) erupsi gunung agung yang terjadi pada tahun 2017 hingga kini masih menyisakan kekhawatiran bagi masyarakat maupun wisatwan, (2) erupsi gunung agung memberikan banyak pelajaran bagi warga masyarakat di sekitar untuk lebih waspada dan melakukan antisipasi apabila suatu ketika gunung agung akan erupsi kembali, (3) erupsi gunung agung dapat menyebabkan atap rumah menjadi ambruk karena tidak mampu menahan berat pasir dari letusan gunung agung, (4) diperlukan suatu konstruksi atap rumah yang tahan terhadap bahaya pasir vulkanik.

\section{METODE}

Metode yang digunakan dalam penelitian ini adalah metode Penelitian dan Pengembangan (Research and Development). Menurut Gall \& Borg (1983: 772) Penelitian dan Pengembangan merupakan salah satu disain penelitian yang bertujuan untuk mengembangkan dan memvalidasi produk. Prototipe model yang dikembangkan adalah konstruksi atap rumah tahan pasir vulkanik. Konstruksi ini diharapkan dapat membantu masyarakat untuk dapat melindungi diri mereka dari bahaya pasir vulkanik dari dalam rumah.

Ada 10 tahapan Penelitian dan Pengembangan seperti yang diusulkan oleh Gall \& Borg (1983: 775-776) yaitu: (1) Penelitian dan pengumpulan informasi; (2) Perencanaan; (3) Pengembangan produk awal; (4) Ujicoba produk awal; (5) Revisi produk; (6) Menguji produk yang sudah direvisi; (7) Merevisi produk yang diperoleh melalui hasil testing; (8) Mentes produk; (9) Merevisi produk akhir; (10) Diseminasi.

Langkah di atas disederhanakan menjadi tiga tahapan sebagaimana dimana dikutip dari Sukmadinata (2008), yaitu (1) Tahap explorasi yang mencakup melakukan analisis kebutuhan; (2) Tahap pengembangan prototype model yang meliputi mendisain model dan mengujicobakan model tersebut; (3) tahap validasi yang memuat validasi ahli.

\section{HASIL DAN PEMBAHASAN}

Hasil penelitian ini menunjukkan jawaban dari ketiga rumusan masalah yang menjadi tujuan utama dalam penelitian ini. Pertama, dalam menganalisis kebutuhan warga terhadap atap rumah yang sesuai diguanakan untuk daerah di sekitar gunung agung, data didapatkan dari hasil observasi. Dalam hal ini, ditemukan bahwa $82 \%$ warga di sekitaran gunung agung menggunakan kayu sebagai rangka konstruksi atap yang digunakan dan jenis atap yang digunakan $95 \%$ warga menggunakan jenis atap genteng dari tanah liat yang terbuat dari tanah liat. 
Menurut Allen (1998) sistem didalam konstruksi bangunan ada 4 yaitu: sistem bangunan, sistem struktural, sistem selubung dan sistem mekanikal. Berikut adalah tabel lembar observasi terhadap analisis kebtuhan warga terhadap konstruksi atap rumah yang tahan terhadap debu vulkanik.

Tabel 1. Hasil Observasi terhadap konstruksi atap yang diperlukan oleh warga sekitar gunung Agung

\begin{tabular}{|c|c|c|c|}
\hline $\mathrm{No}$ & Deskripsi & $\mathrm{Ya}$ & Tidak \\
\hline 1 & $\begin{array}{l}\text { Konstruksi atap } \\
\text { menggunakan kayu } \\
\text { merupakan konstruksi yang } \\
\text { sesuai untuk daerah kawasan } \\
\text { gunung api }\end{array}$ & $40 \%$ & $60 \%$ \\
\hline 2 & $\begin{array}{l}\text { Konstruksi atap } \\
\text { menggunakan beton } \\
\text { merupakan konstruksi yang } \\
\text { sesuai untuk daerah kawasan } \\
\text { gunung api }\end{array}$ & $11 \%$ & $9 \%$ \\
\hline 3 & $\begin{array}{l}\text { Konstruksi atap } \\
\text { menggunakan baja ringan } \\
\text { merupakan konstruksi yang } \\
\text { sesuai untuk daerah kawasan } \\
\text { gunung api }\end{array}$ & $82 \%$ & $18 \%$ \\
\hline 4 & $\begin{array}{l}\text { Jenis atap menentukan daya } \\
\text { tahan rumah terhadap suhu } \\
\text { yang berubah-ubah }\end{array}$ & $100 \%$ & $0 \%$ \\
\hline 5 & $\begin{array}{l}\text { Saya menggunakan jenis } \\
\text { atap genteng dari tanah liat } \\
\text { di rumah saya }\end{array}$ & $85 \%$ & $15 \%$ \\
\hline 6 & $\begin{array}{l}\text { Saya menggunakan jenis } \\
\text { atap asbes di rumah saya }\end{array}$ & $10 \%$ & $90 \%$ \\
\hline 7 & $\begin{array}{l}\text { Saya menggunakan jenis } \\
\text { atap metal di rumah saya }\end{array}$ & $5 \%$ & $95 \%$ \\
\hline 8 & $\begin{array}{l}\text { Saya memerlukan konstruksi } \\
\text { atap yang dapat tahan } \\
\text { terhadap suhu yang berubah- } \\
\text { ubah }\end{array}$ & $100 \%$ & $0 \%$ \\
\hline 9 & $\begin{array}{l}\text { Saya memerlukan konstruksi } \\
\text { atap yang kuat menahan } \\
\text { beban genteng serta abu } \\
\text { yang jatuh diatas permukaan } \\
\text { genteng }\end{array}$ & $100 \%$ & $0 \%$ \\
\hline 10 & $\begin{array}{l}\text { Saya memerlukan konstruksi } \\
\text { atap yang kokoh dan tahan } \\
\text { terhadap abu vulkanik }\end{array}$ & $100 \%$ & $0 \%$ \\
\hline
\end{tabular}

Dari hasil observasi diatas jelas menunjukkan bahwa warga memerlukan konstruksi atap yang kuat menahan beban genteng serta abu yang jatuh diatas permukaan genteng dan tahan terhadap suhu yang berubah-ubah secara ekstrim seperti yang ada di kawasan gunung Agung. Hal ini di dukung oleh pendapat Purwanto (2017) yang menyatakan bahwa atap adalah bagian dari suatu bangunan yang berfungsi sebagai penutup seluruh ruangan yang ada dibawahnya dari pengaruh panas, hujan, angin, debu, termasuk juga untuk keperluan perlindungan, yang terdiri dari dua komponen yaitu konstruksi rangka atap (kudakuda) dan konstruksi penutup. Dimana material yang digunakan untuk konstruksi menentukan kenyamanan bagi penghuninya.

Dengan mempertimbangkan berat atap serta bahan dan bentuk penutupnya, maka konstruksi kuda-kuda satu sama lain akan berbeda, tetapi setiap susunan rangka batang harus merupakan satu kesatuan yang kokoh yang nantinya memikul beban yang bekerja tanpa mengalami perubahan (Tamrin, 2008). Salah satunya adalah konstruksi baja ringan sebagai alternatif pengganti konstruksi kayu, khususnya pada rumah tinggal. Baja ringan adalah baja dengan kualitas tinggi yang bersifat ringan dan tipis, namun kekuatannya tidak kalah jika dibandingkan dengan baja konvensional. Salah satu keunggulan dari baja ringan adalah dalam waktu pelaksanaannya lebih cepat di bandingkan dengan material kayu, dimana baja ringan tidak akan terkena rayap atau tidak mudah lapuk dan juga baja ringan mempunyai kekuatan struktur yang lebih kuat di bandingkan struktur dari kayu. Proses pabrikasi dan jasa konstruksi yang berkembang pesat pada kuda-kuda menjadikan kuda-kuda baja ringan menjadi salah satu pilihan masyarakat. Material yang sering digunakan dalam konstruksi kuda-kuda baja ringan adalah profil $\mathrm{C}$ untuk rangka atap dan profil U untuk struktur kuda-kudanya.

Dalam proses pabrikasi dan konstruksinya, banyak type (model) kuda-kuda yang dapat digunakan, sehingga hal ini perlu dilakukan analisa terhadap berat dan kuat konstruksi kuda-kuda, dengan tujuan konstruksi aman dan efisien, yaitu dengan menganalisis konstruksi kuda-kuda baja ringan dengan 2 tipe kuda-kuda dan bentang 10 meter, guna mendapatkan nilainilai gaya dalam dan dimensi profil baja ringan yang digunakan

Tujuan yang kedua adalah mengidentifikasi jenis atap rumah yang tahan terhadap bahaya pasir vulkanik, dalam hal ini data didapatkan dari studi dokumentasi terhadap perbandingan sifat beberapa jenis maerial untuk rangka dan jenis atap yang sesuai untuk kawasan gunung api. Fungsi rangka atap yang lebih spesifik 
adalah menerima beban oleh bobot sendiri, yaitu beban kuda-kuda dan bahan pelapis berarah vertikal kemudian meneruskannya pada kolom dan pondasi, serta dapat berfungsi sebagai penahan tekanan angin muatan yang berarah horizontal pada gevel. (Hesna dkk, 2009). Pemilihan Material yang sustainable adalah suatu topik yang mengundang perdebatan. "Sustainable" dapat berarti material yang digunakan adalah ramah lingkungan, hemat energi dapat bertahan lama dan dapat dipergunakan lagi atau di recycle kembali. Perbandingan dari empat jenis material yang umum digunakan untuk rangka atap adalah sebagai berikut.

Tabel 2. Perbandingan sifat beberapa jenis material

\begin{tabular}{|c|c|c|c|}
\hline Parameter & Kayu & Beton & Baja Ringan \\
\hline $\begin{array}{l}\text { Tahan } \\
\text { Cuaca }\end{array}$ & $\begin{array}{l}\text { Perlu } \\
\text { treatment }\end{array}$ & $\mathrm{Ya}$ & $\mathrm{Ya}$ \\
\hline $\begin{array}{l}\text { Tahan } \\
\text { Rayap }\end{array}$ & $\begin{array}{l}\text { Perlu } \\
\text { treatment }\end{array}$ & $\mathrm{Ya}$ & $\mathrm{Ya}$ \\
\hline $\begin{array}{l}\text { Tahan } \\
\text { Karat }\end{array}$ & $\mathrm{Ya}$ & $\mathrm{Ya}$ & $\begin{array}{l}\text { Ya dengan } \\
\text { galvanisasi }\end{array}$ \\
\hline Bobot & Sedang & Berat & Ringan \\
\hline Kekuatan & $\begin{array}{l}\text { Rendah- } \\
\text { Sedang }\end{array}$ & Kuat & Sangat Kuat \\
\hline Harga & Mahal & Murah & Sedang \\
\hline $\begin{array}{l}\text { Biaya } \\
\text { energi } \\
\text { produksi }\end{array}$ & $\begin{array}{l}\text { Negatif, } \\
\text { menghasilka } \\
\mathrm{n} \\
\text { energi }\end{array}$ & $\begin{array}{l}\text { Tinggi, } \\
\text { pembak } \\
\text { aran } \\
\text { kapur } \\
\text { untuk } \\
\text { semen }\end{array}$ & $\begin{array}{l}\text { Tinggi, } \\
\text { untuk } \\
\text { peleburan } \\
\text { dan } \\
\text { galvanisasi }\end{array}$ \\
\hline $\begin{array}{l}\text { Waktu } \\
\text { produksi }\end{array}$ & $\begin{array}{l}\text { Lama, } \\
\text { minimal } 10 \\
\text { tahun } \\
\end{array}$ & Cepat & Cepat \\
\hline $\begin{array}{l}\text { Kerusakan } \\
\text { Lingkung } \\
\text { an } \\
\text { akibat } \\
\text { produksi }\end{array}$ & $\begin{array}{l}\text { Besar, } \\
\text { akibat } \\
\text { penebangan } \\
\text { Hutan } \\
\text { Tropis }\end{array}$ & $\begin{array}{l}\text { Sedang, } \\
\text { akibat } \\
\text { penggali } \\
\text { an dan } \\
\text { penamb } \\
\text { angan, } \\
\text { polusi } \\
\text { hasil } \\
\text { pembak } \\
\text { aran }\end{array}$ & $\begin{array}{l}\text { Sedang, } \\
\text { akibat } \\
\text { penggalian } \\
\text { dan } \\
\text { penambanga } \\
\text { n, polusi } \\
\text { karena } \\
\text { peleburan } \\
\text { dan } \\
\text { galvanisasi }\end{array}$ \\
\hline $\begin{array}{l}\text { Ramah } \\
\text { Lingkung } \\
\text { an }\end{array}$ & $\begin{array}{l}\text { Ya bila } \\
\text { diambil } \\
\text { dari HTI, } \\
\text { Tidak } \\
\text { bila diambil } \\
\text { dari } \\
\text { Hutan } \\
\text { Tropis }\end{array}$ & $\mathrm{Ya}$ & $\begin{array}{l}\text { Ya, karena } \\
\text { lebih } \\
\text { tahan lama } \\
\text { dari kayu }\end{array}$ \\
\hline $\begin{array}{l}\text { Daur } \\
\text { ulang }\end{array}$ & $\begin{array}{l}\text { Tidak, tapi } \\
\text { dapat } \\
\text { diproduksi } \\
\text { secara alam }\end{array}$ & $\begin{array}{l}\text { Ya, } \\
\text { tetapi } \\
\text { memaka } \\
\text { n energi }\end{array}$ & $\begin{array}{l}\text { Ya, tetapi } \\
\text { memakan } \\
\text { energi }\end{array}$ \\
\hline
\end{tabular}

\begin{tabular}{|l|l|l|l|}
\hline $\begin{array}{l}\text { Kemudah } \\
\text { an } \\
\text { Konstruks } \\
\text { i }\end{array}$ & Mudah & $\begin{array}{l}\text { Sulit } \\
\text { karena } \\
\text { berat }\end{array}$ & Sedang \\
\hline $\begin{array}{l}\text { Peralatan } \\
\text { Khusus }\end{array}$ & $\begin{array}{l}\text { Sedang } \\
\text { (Bor, } \\
\text { Pahat, } \\
\text { Obeng, } \\
\text { Gergaji) }\end{array}$ & $\begin{array}{l}\text { Ya } \\
\text { (Crane, } \\
\text { mixer, } \\
\text { bekistin } \\
\text { g, } \\
\text { pompa } \\
\text { beton) }\end{array}$ & $\begin{array}{l}\text { Sedang } \\
\text { (Bor, } \\
\text { Tang, mesin } \\
\text { potong) }\end{array}$ \\
\hline
\end{tabular}

Dari tabel 2 di atas dapat ditarik kesimpulan bahwa material kayu hanya bersifat ramah lingkungan bila diambil dari hutan tanaman industri (HTI), sedangkan bila tidak, maka akan merugikan lingkungan (pengrusakan hutan yang berfungsi menyerap $\mathrm{CO} 2$ ). Material kayu konstruksi yang memenuhi syarat diatas masih dalam penelitian dan belum tersedia banyak, umumnya berupa Glulaminated Wood (Glulam) dan Engineered Bamboo. Diluar itu, material baja dapat bersifat ramah lingkungan bila tidak mudah berkarat dan dapat didaur ulang dengan murah, walaupun energi yang dibutuhkan untuk produksi awalnya tinggi. Dan dari segi biaya, untuk bentang kuda-kuda $6 \mathrm{~m}$, biaya baja ringan lebih murah dibandingkan kayu jati, tetapi pada bentang 12 dan $15 \mathrm{~m}$ biaya penggunaan baja ringan lebih mahal mengingat bertambahnya material baja ringan untuk mengantisipasi lentur yang merupakan kelemahan baja ringan. Darmawan (2015), juga mengatakan bahwa atap baja ringan lebih efektif dan efisien dibanding kayu. Dan Sinaga (2015), memperlihatkan bahwa penggunaan materil baja ringan lebih ekonomis dari baja konvensional.

Sebagai salah satu material yang bisa digolongkan "ramah lingkungan" dalam kadar tertentu, maka keuntungan dari penggunaan material baja ringan ini adalah sbb: Tahan lama: tahan karat, cuaca, rayap, tidak mudah terbakar (non-combustible) (Bila menggunakan AZ-150 gr/m2 atau Z-220 $\mathrm{gr} / \mathrm{m} 2$, dan sekrup AS-3566, untuk daerah pantai harus menggunakan coating dan sekrup yang marine quality). Untuk melindungi material baja mutu tinggi dari korosi, baja harus diberikan lapisan pelindung (coating) secara memadai. Jenis coating pada baja ringan adalah galvanized, galvalume, atau sering juga disebut sebagai zincalume dan 
ZAM, dikembangkan sejak 1985, dengan lapisan pelindung yang terdiri dari: $96 \%$ zinc, 6\% aluminium, dan 3\% magnesium 9 (Iden Wildensyah ; 2013). Beban yang terjadi menggunakan Peraturan Pembebanan Indonesia Untuk (PPI) Gedung tahun 1983, Peraturan Muatan Indonesia (PMI) 1970, Standar Nasional Indonesia (SNI) 2002 dan Pedoman Perencanaan Pembebanan (PPP) Untuk Rumah dan Gedung, SKBI1.3.53.1987.

1. Ketahanan ZincAlum adalah sekitar 3-4 x ketahanan Galvanize, terutama pada daerah pantai.

2. Ringan dan mudah diangkut dan dipasang, mengurangi beban gempa pada struktur

3. Kuat, daya dukung beban besar, karena menggunakan baja mutu tinggi

4. Tidak memerlukan peralatan dan tukang khusus, cepat dan mudah pemasangannya

5. Dapat diaplikasikan untuk rangka atap, dan rangka utama rumah 1-2 lantai

6. Dapat di daur ulang setelah jangka pemakaian yang lama, limbah tidak merusak lingkungan.

Adapun beberapa bahan penutup atap yang bisa diterapkan pada daerah pegunungan antara lain asbes, seng dan genting tanah liat (Ramayana, 2004). Ada 3 jenis atap yang digunakan sebagai perbandingan dalam penelitian ini, yaitu jenis genteng dari tanah liat, metal dan asbes. Berikut adalah hasil studi dokumentasi terhadap 3 jenis atap tersebut:

Tabel 3. Perbandingan jenis genteng

\begin{tabular}{|l|l|l|l|l|}
\hline No & Deskripsi & $\begin{array}{l}\text { Tanah } \\
\text { liat }\end{array}$ & Metal & Asbes \\
\hline 1 & $\begin{array}{l}\text { Tahan } \\
\text { Perubahan } \\
\text { Cuaca Ekstrim }\end{array}$ & tidak & ya & tidak \\
\hline 2 & $\begin{array}{l}\text { Tahan } \\
\text { Perubahan } \\
\text { Cuaca Non } \\
\text { ekstrim }\end{array}$ & ya & ya & ya \\
\hline 3 & Bobot & berat & sedang & ringan \\
\hline 4 & Kekuatan & kuat & $\begin{array}{l}\text { Sangat } \\
\text { kuat }\end{array}$ & $\begin{array}{l}\text { Mudah } \\
\text { pecah }\end{array}$ \\
\hline 5 & Harga & sedang & mahal & murah \\
\hline 6 & $\begin{array}{l}\text { Waktu } \\
\text { produksi }\end{array}$ & cepat & lama & cepat \\
\hline
\end{tabular}

Berdasarkan tabel 3 dapat ditarik kesimpulan bahwa jenis genteng metal merupakan jenis genteng yang sangat kuat dan tahan terhaddap cuaca yang berubah secara ekstrim meskipun memang apabila dilihat dari segi harga dan waktu produksinya lebih lama dibandingkan jenis genteng yang berbahan tanah liat dan juga asbes. Genteng tanah liat adalah genteng yang terbuat dari tanah liat dan dibakar dengan suhu tinggi. Bentuk genteng tanah liat ini juga beragam antara lain genteng kodok dan genteng plentong. Genteng kodok memiliki berat $1,5-1,8 \mathrm{~kg} / \mathrm{buah}$ dengan kebutuhan per meter persegi 21-25 buah. Sedangkan genteng plentong memiliki berat $1,5 \mathrm{~kg} / \mathrm{buah}$ dengan kebutuhan per meter persegi 25 buah. Genteng metal terbuat dari pelat baja metal yang diberi lapisan galvanis (zink). Ada dua model genteng berlapis pasir kwarsa dan genteng metal dicat. Di lapangan terdapat banyak spesifikasi genteng metal, sebagai contoh ada yang memiliki ukuran $410 \mathrm{~mm}$ x $710 \mathrm{~mm}$, namun ada juga yang berukuran $370 \mathrm{x}$ $1320 \mathrm{~mm}$. Untuk itu survei material genteng metal dilakukan dengan satuan m2. Atap asbes gelombang/asbes genteng atau Fibersemen adalah material yang dibuat dari bahan asbes. Di pasaran terdapat tiga type yaitu type gelombang 5,5, type gelombang 14 dan type asbes genteng.

Terkait dengan kedua hasil studi dokumentasi tersebut diatas, maka jenis konstruksi atap rumah yang tahan terhadap bahaya pasir vulkanik adalah konstruksi yang menggunakan baja ringan dan juga jenis atap dari metal yang kuat dan tahan terhadap cuaca yang berubah secara ekstrim seperti daerah gunung agung yang suhu normalnya $29^{\circ} \mathrm{CC}$ dan bisa berubah ektrim karna panasnya semburan abu vulkanik hingga $40^{\circ} \mathrm{CC}$.

Tujuan penelitian yang ketiga yaitu mendesain konstruksi atap rumah bagi warga di sekitar gunung agung agar tahan terhadap pasir vulkanik. Berdasarkan SNI 03-1726-2002, Tata Cara Perencanaan Ketahanan Gempa Untuk Bangunan oleh Dinas Pekerjaan Umum tahun 2006, ada 3 prinsip dalam pembangunan rumah tahan gempa yaitu: (1) Denah yang sederhana dan simetris, (2) Bahan bangunan harus seringan mungkin, (3) Sistem konstruksi yang memadai dalam mengurangi resiko gempa. Dalam mendesain konstruksi atap 
sistem sambungan dan bentuk profil yang digunakan, maka walaupun memungkinkan untuk merencanakan rangka atap secara 3D, namun rangka atap sebaiknya direncanakan sebagai rangka batang dua dimensi (2D).

Arti dan fungsi konstruksi atap ialah sebagai pelindung manusia terhadap cuaca. Dinding dapat ditinggikan. Tetapi tidak mungkin menghapuskan atap, kenapa kita kehilangan tujuan suatu bangunan. Sebuah bangunan dibagi-bagi oleh atap menjadi bagian rumah, menjadi volume yang jelas, menjadi kesatuan yang dapat diidentifikasi (Frick, 1980). Dalam perencanaan praktis sehari-hari, rangka atap dimodelkan sekaligus sebagai satu kesatuan, dan kemudian dilakukan analisis dan disain untuk setiap rangka batang bidang yang menyusunnya. Rangka batang bidang ini akan memikul beban vertikal dan beban lateral yang terjadi pada arah memendek. Sedangkan beban angin pada arah memanjang akan dipikul oleh rangka bresing vertikal, bukan oleh rangka batang bidang. Untuk aplikasi rangka atap pada struktur yang tidak memiliki balok ring melintang ruangan, sebaiknya diberikan juga bresing horizontal level bawah, agar bila terjadi batang bawah tertekan, biasanya karena beban gempa, maka bresing ini masih dapat menahan.

Ada beberapa faktor yang menentukan dalam perencanaan rangka atap:

1. Bentuk dan sudut Atap: Pelana, Perisai, Joglo

2. Beban material penutup atap (roof tile)

3. Jarak Gording/Reng

4. Jarak Rangka Bidang

5. Kecepatan angin rencana dan beban air hujan

6. Panjang batang tekan maksimum atau Lambda maks

7. Panjang batang tarik maksimum atau Lambda maks

Sudut atap sebaiknya tidak terlalu rendah, karena akan mengurangi tinggi rangka dan mengurangi daya dukungnya. Sudut juga tergantung pada sudut minimum yang diijinkan untuk jenis penutup atap tertentu. Kisaran harga sudut atap antara $10-60$ derajat, dengan nilai optimal biasanya antara 20-40 derajat. Namun, secara umum, untuk bahan kering sudut istirahat meningkat dengan meningkatnya ukuran butir, tetapi biasanya terletak di antara sekitar $30^{\circ}$ dan $37^{\circ}$ (Nelson, 2003).

Pemilihan material penutup atap tergantung sifat tahan jamur, tahan cuaca, sound proof, perubahan warna, tahan sinar UV, tahan pecah, kekedapan terhadap air, bobot, harga, dsb. Jarak rangka biasanya $1.0 \mathrm{~m}$ - $1.5 \mathrm{~m}$, tergantung berat penutup atap dan kecepatan angin yang digunakan. Pada daerah salju, jarak rangka dapat mencapai $0.60 \mathrm{~m}$. Jarak gording atau reng berkisar antara $0.25 \mathrm{~m}$ $-1.2 \mathrm{~m}$, tergantung jenis penutup atap/genteng dan ukuran rengnya. Kecepatan angin rencana minimal dianjurkan $50 \mathrm{~km}$ per jam, atau sebaiknya $80 \mathrm{~km}$ per jam, mengingat keadaan cuaca dewasa ini belum dapat diperkirakan dengan baik karena efek "Global Warming". Untuk daerah pantai sebainya $80-120 \mathrm{~km} / \mathrm{jam}$. Beban air hujan rencana dapat diambil ketebalam minimal $50 \mathrm{~mm}$ atau tergantung jenis atap yang digunakan. Minimal digunakan $20 \mathrm{~kg} / \mathrm{m} 2$ untuk air hujan. Karena cuaca yang tidak menentu dewasa ini, kombinasi antara angin dan hujan dengan reduksi tertentu sebaiknya tetap digunakan. Beban hidup pekerja umumnya tidak begitu menentukan karena biasanya hanya beberapa pekerja yang bekerja diatas atap, dan mereka umumnya menggunakan papan pembagi beban. Beban konstruksi yang harus diperhatikan adalah konsentrasi penumpukan genteng sebelum dipasang. Beban hidup pekerja dapat disimulasikan sebagai beban terpusat $100 \mathrm{~kg}$ berjalan pada setiap titik buhul suatu rangka batang bidang atau sebagai beban terbagi merata dalam keadaan tidak ada angin dan hujan.

Batasan lainnya adalah kelangsingan maksimum batang tekan yang biasanya dibatasi $\mathrm{Ld}=\mathrm{L} / \mathrm{rmin}<=120$ untuk batang tekan di bagian atas rangka dan untuk batang tarik di bawahrangka L/rmin $<=200$. Panjang bebas yang tidak terkekang secara lateral juga dapat direduksi dengan memperhitungkan pengaruh jarak reng dan penambahan bresing lateral. Perencanaan konstruksi genteng dengan spesifikasi sebagai berikut : 
- Sudut kemiringan atap yaitu 350

- Jarak antar kuda-kuda adalah 1,2 m

- Jarak antar span/reng adalah $25 \mathrm{~cm}$



Gambar 1. Foto atap metal warga

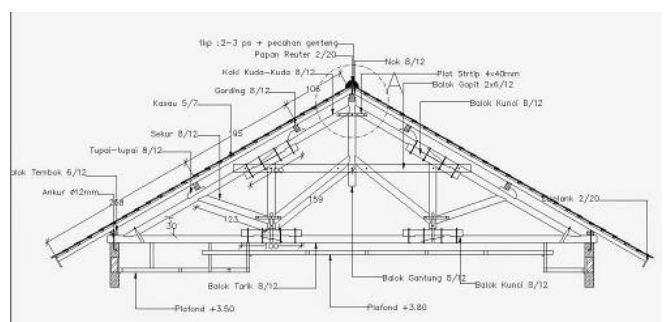

Gambar 2. konstruksi kerangka atap baja ringan

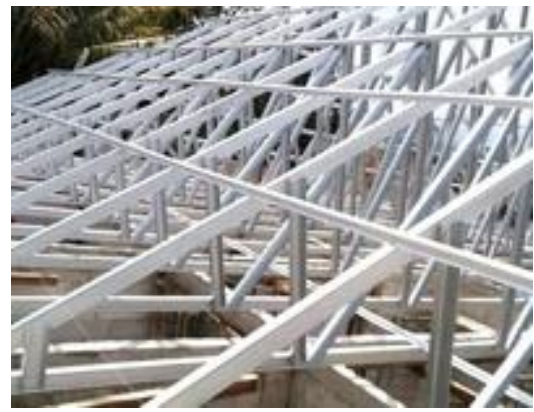

Gambar 3. Foto konstruksi atap menggunakan baja ringan

\section{Struktur rangka atap :}

- Spesifikasi Mutu baja : G 550 (kuat tarik $550 \mathrm{Mpa} / 5500 \mathrm{~kg} / \mathrm{cm} 2$ )

- Campuran Komposisi baja : $55 \%$ aluminium, $43.5 \%$ zinc, $1.5 \%$ silicone.

\section{Bagian Profil Baja Ringan:}

\section{Rangka kuda-kuda :}

- Profile canal C 75.100 / C 75.75

- Tebal $1.00 \mathrm{~mm} / 0.75 \mathrm{~mm}$ (untuk top \& bottom chord) (tergantung beban dan bentangan)

- Tebal $0.75 \mathrm{~mm}$ (untuk web)

Reng :

- Canal profile U dengan tebal $0.45 \mathrm{~mm}$
Aksesoris :

- Bracket L, dengan profil L tebal $1.5 \mathrm{~mm}$

- Dynabolt, dengan diameter $12 \mathrm{~mm}$, panjang $100 \mathrm{~mm}$

Jadi disini bentuk atap dimodelkan secara Parametrik, tanpa perlu menggambar. Panjang danlebar suatu atap dapat diubah setiap waktu, dan program akan menghasilkan model yang barudengan cepat. Untuk membuat model atap secara fleksibel, selain disediakan bentuk ataptertentu ayng sering digunakan : Persegi, L, C/U, T, H, Z, Box, disediakan juga fasilitas untukmengedit tonjolan atap atau memasukkan void pada atap. Canopy dan Overhang juga dapatdimodelkan dengan mudah.

Rangka Atap berdasarkan data diatas, maka garis tepi overhang, balok ring, jurai dalam, jurai luar, garisbubung, gording/reng, rangka batang atap, dan rangka tambahan (jack rafter) akan dihitungdan digambar secara otomatis. Bentuk rangka atap tersedia dalam beberapa pilihan:Segitiga/Joglo1/Joglo2/Flat top, dengan alternatif bentuk diagonal/double $\mathrm{W}$, atau $\mathrm{W}+$ batang vertikal. Batang pada rangka atap dibedakan menjadi: batang bawah, batang atas, batangvertikal, batang diagonal, batang overhang, bresing vertikal, dan bresing horizontal. Bila batangmenerima beban merata atau beban lentur, maka dapat dimodelkan sebagai elemen frame. Pemodelan Tumpuan tumpuan secara otomatis akan ditempatkan pada pertemuan rangka batang dan balok ring.Bila diperlukan tumpuan tambahan, dapat dimodelkan juga garis dinding yang akan digunakansebagai tumpuan. Pada saat pembuatan model suatu rangka batang atap, pada perpotonganrangka dan garis dinding dalam tersebut akan ditambahkan suatu tumpuan dan titik padarangka batang tersebut akan digeser ke arah tumpuan tersebut.

Struktur rangka atap adalah salah satu bagian penting dalam konstruksi bangunan. Wicaksono (2011) berpendapat bahwa, struktur atap adalah bagian bangunan yang menahan atau mengalirkan beban-beban dari atap ke elemen struktur kolom. Beban yang diperoleh dari atap tidak semata dari bahan dan rangkaiannya saja, namun juga beban angin, hujan dan beban lain yang bersifat dinamis. 
Ada beberapa penelitan terdahulu yang telah membahas penggunaan atap baja ringan. Diantaranya adalah Irianto (2013), hasil penelitiannya menyatakan bahwa penggunaan kuda-kuda kayu jati lebih berat dibanding baja ringan. Dan dari segi biaya, untuk bentang kuda-kuda $6 \mathrm{~m}$, biaya baja ringan lebih murah dibandingkan kayu jati, tetapi pada bentang 12 dan $15 \mathrm{~m}$ biaya penggunaan baja ringan lebih mahal mengingat bertambahnya material baja ringan untuk mengantisipasi lentur yang merupakan kelemahan baja ringan.

\section{KESIMPULAN}

Ada tiga hal yang dapat disimpulkan dalam penelitian ini. Pertama, warga memerlukan konstruksi atap yang kuat menahan beban genteng serta abu yang jatuh diatas permukaan genteng dan tahan terhadap suhu yang berubah-ubah secara ekstrim seperti yang ada di kawasan gunung Agung. Kedua, jenis konstruksi atap rumah yang tahan terhadap bahaya pasir vulkanik adalah konstruksi yang menggunakan baja ringan dan juga jenis atap dari metal yang kuat dan tahan terhadap cuaca yang berubah secara ekstrim seperti daerah gunung agung yang suhu normalnya $29^{\circ} \mathrm{C}$ dan bisa berubah ektrim karna panasnya semburan abu vulkanik hingga $40^{\circ} \mathrm{C}$. Ketiga, desain konstruksi atap rumah bagi warga di sekitar gunung agung agar tahan terhadap pasir vulkanik dengan bentuk rangka atap yang tersedia dalam beberapa pilihan yakni bentuk kosntruksi atap segitiga, joglo type 1 , joglo type 2, flat top dengan alternatif bentuk diagonal atau double $\mathrm{W}$, atau $\mathrm{W}+$ batang vertikal. Batang pada rangka atap dibedakan menjadi: batang bawah, batang atas, batang vertikal, batang diagonal, batang overhang, bresing vertikal, dan bresing horizontal.

\section{UCAPAN TERIMAKASIH}

Penelitian ini adalah bagian dari Penelitian Dasar Pemula yang dibiayai oleh Kementrian Riset dan Pendidikan Tinggi (KEMENRISTEKDIKTI) dan di dukung oleh Politeknik Internasional Bali sebagai institusi asal penulis.

\section{REFERENSI}

Allen, Edward. (1998). Dasar - Dasar Konstruksi Bangunan, Erlangga. Jakarta.

Borg, W.R dan Gall, M.D. (1983). Educational Research: An Introduction. New York and London: Longman.

Dinas Pekerjaan Umum, (2006). Pedoman Teknis Rumah dan Bangunan Gedung Tahan Gempa. Jakarta.

Frick, H.,Setiawan. (1980). Ilmu konstruksi Bangunan 2. Kanisius. Yogyakarta.

Hesna, Yevri dkk. (2009). Komparasi Penggunaan Kayu dan Baja Ringan sebagai Konstruksi Rangka Atap. Universitas Andalas. Padang

Irianto. (2013). Komparasi Penggunaan Kayu Dan Baja Ringan Sebagai Konstruksi Rangka Atap. Jurnnal Ilmu Pengetahuan dan Teknologi, Vol 3 (11) : 45-51

Nelson, Stephen A. (2003). Mass-Wasting. Physical Geology http://www.tulane. edu/ sanelson/geol111/masswasting.ht m (diakses 26 Agustus 2020).

Ramayana, Harry. (2004). Kajian Bahan Penutup Atap Bangunan di Daerah Pegunungan. Semarang: Seminar Arsitektur Fakultas Teknik Jurusan Arsitektur Unversitas Katolik Soegijapranata.

Sinaga. (2015). Perencanaan Rangka Atap Baja Ringan Berdasarkan SNI 7971:2013. Jurusan Teknik Sipil Fakultas Teknik Universitas Sumatra Utara

Standar Nasional Indonesia. (2002). Tata Cara Perencanaan Struktur Baja Untuk Bangunan Gedung, SNI-03-1729-2002, Badan Standarisasi Nasional, Bandung.

Tamrin, A. G. (2008). Teknik Konstruksi Bangunan Gedung Sederhana Jilid 2 untuk SMK. Jakarta: Pusat perbukuan Departemen Pendidikan Nasional, hal: $152-155$.

Wildensyah, Iden. (2013). Rangka Atap Baja Ringan Untuk Semua. Edisi kedua. Alfabeta, Bandung, Indonesia.

Wicaksono. (2011). Panduan Konsumen Memilih Konstruksi Baja Ringan. Yogyakarta: ANDI. 